important factors in the incidence of postoperative pulmonary complications. By random selection we obtained groups that were broadly comparable with respect to these factors.

The two studies show conclusively that either a single dose or an infusion of doxapram given concurrently with morphine significantly reduces the incidence of persistent coughing or expectoration of purulent sputum or both during the first five days after operation. In contrast, these treatments fail to reduce the incidence of abnormal physical signs and radiological changes. This may indicate the presence of different aetiological mechanisms. Coughing and the expectoration of sputum suggest infection in the bronchial tree, whereas $x$-ray changes indicate marked alveolar collapse. It is difficult to envisage the means by which a short-acting drug such as doxapram reduces the former complications. The abolition of morphine-induced respiratory depression by doxapram cannot be the sole factor, since those patients given morphine and naloxone did not benefit to the same extent. More probably the brief period of hyperventilation induced by doxapram, even in the presence of morphine, ${ }^{1}$ is important. It is equally difficult to explain the significant difference in mean arterial oxygen tension on the fifth day after a single injection of doxapram (fig). Winnie et $a l^{4}$ suggested that a reduction in microatelectasis could result from hyperventilation, or that doxapram could increase pulmonary vascular perfusion. In our study there was no evidence of pronounced cardiovascular stimulation. In any event, it seems unlikely that a rise in cardiac output immediately after operation would be manifested by a raised $\mathrm{PaO}_{2}$ five days later.
The present findings are at variance with those of Gupta and Dundee $^{1}$ with respect to the influence of a single dose of doxapram on morphine dosage. In this study it resulted in a significant increase in the amount of morphine required, whereas this was not observed in the study of Gupta and Dundee. This is more likely to be due to an arousal effect of doxapram than to a true antagonism of morphine-induced analgesia. We have no reason to doubt previous findings, that doxapram did not reduce the analgesic efficacy of morphine and pethidine in experimentally induced pain.

The clinical importance of these findings must not be underestimated. Cough and the expectoration of purulent sputum are the most distressing of the postoperative pulmonary complications so far as the patient is concerned. There is good evidence to show that these are reduced by safe doses of doxapram.

THG is grateful for a research grant from the endowment funds of the Royal Victoria Hospital, Belfast, which enabled him to carry out this work. We are grateful to A H Robins Company Ltd for supplies of doxapram.

\section{References \\ ${ }^{1}$ Gupta, P K, and Dundee, J W, Anaesthesia, 1974, 29, 33. \\ 2 Gupta, P K, and Dundee, J W, Anaesthesia, 1974, 29, 40. \\ 3 Cox, P, Miller, L, and Petty, T L, Chest, 1973, 63, 517. \\ ${ }^{4}$ Winnie, A P, et al, Anesthesia and Analgesia, Current Researches, 1971, 50, 1043. \\ ${ }^{5}$ Dundee, J W, Gupta, P K, and Jones, C J, British Fournal of Pharma- cology, 1973, 48, 326P.}

\title{
Three-day and ten-day chemotherapy for urinary tract infections in general practice
}

\author{
C A C CHARLTON, A CROWTHER, J G DAVIES, J DYNES, M W A HAWARD, \\ P G MANN, S RYE
}

\section{Introduction}

Most women with frequency and dysuria are treated with antibiotics. It has been established ${ }^{12}$ that in the community about half of these women will have bacteriuria, for which a course of an appropriate antibiotic is indicated. Several studies ${ }^{34}$ carried out in general practice indicate that $80-90 \%$ of these infections are due to organisms sensitive to ampicillin or one of its analogues. There is, however, no authoritative indication of the length of time the antibiotics must be given to eradicate the infection. We describe here our attempt to answer this question. practice a three-day course of amoxycillin was as effective as a 10-day course of the same drug in the same dose. Relief of symptoms was equal in both groups and bacteriuria was eliminated equally successfully by both regimens. There was no significant difference between the two groups in the incidence of side effects from the drugs. The financial saving which could accrue from adopting this therapeutic regimen would be significant.

\section{Department of Urology, St Martin's Hospital, Bath}

C A C CHARLTON, MS, FRCS, consultant urological surgeon

Public Health Laboratory, Royal United Hospital, Bath P G MANN, MD, MRCPATH, director

St Chad's Surgery, Midsomer Norton, Avon

$M$ W A HAWARD, $M B, B C H I R$, general practitioner

J G DAVIES, MB, DOBSTRCOG, general practitioner

J RYE, MB, DOBSTRCOG, general practitioner

J DYNES, SRN, practice nursing sister

A CROWTHER, SRN, practice nursing sister

\section{Patients and methods}

All non-pregnant women who attended a general practice surgery complaining of frequency, dysuria, or loin pain entered the trial. The drug chosen for trial was amoxycillin (Amoxil). This is a semisynthetic penicillin with the same broad spectrum of activity as ampicillin, but with the advantages of better absorption from the gut and additional enhancement of bactericidal activity. Two drug regimens were used. Patients first seen during even-numbered months - that is, February, April, June, etc-were given nine capsules of Amoxil $500 \mathrm{mg}$ and instructed to take 1 capsule three times a day for three days. Patients who attended first during odd-numbered months-that is, January, March, May, etc-were given 30 capsules of amoxycillin $500 \mathrm{mg}$ and instructed to take 1 capsule three times a day for 10 days.

Two samples of urine for culture were taken from each patient before treatment began, one on the day of attendance at the surgery and the second the next morning, before the patient took the first capsule of amoxycillin. A standard inoculum of urine was collected with 
TABLE I-Distribution of ampicillin-sensitive organisms in the two treatment groups in patients followed for six weeks

\begin{tabular}{|c|c|c|c|c|c|c|c|}
\hline $\begin{array}{l}\text { 10-Day regimen } \\
\text { 3-Day regimen }\end{array}$ & $\begin{array}{c}\text { No of } \\
\text { patients } \\
58 \\
52\end{array}$ & $\begin{array}{c}\text { Escherichia } \\
\text { coli } \\
45 \\
42\end{array}$ & $\begin{array}{c}\text { Proteus } \\
\text { sp } \\
4 \\
5\end{array}$ & $\begin{array}{c}\text { Micrococcus } \\
\text { sp } \\
5 \\
2\end{array}$ & $\begin{array}{c}\text { Klebsiella } \\
\text { sp } \\
2 \\
1\end{array}$ & $\begin{array}{c}\text { Staphylococcus } \\
\text { albus } \\
2 \\
1\end{array}$ & $\begin{array}{c}\text { Streptococcus } \\
\text { faecalis } \\
0 \\
1\end{array}$ \\
\hline Total & 110 & 87 & 9 & 7 & 3 & 3 & 1 \\
\hline
\end{tabular}

the Mackey-Sandys dip-inoculum spoon. ${ }^{5}$ After overnight incubation in the laboratory at $36 \mathrm{C}$ colony counts were made and potential pathogens were picked for drug sensitivity appraisal and any additional confirmatory tests needed for final identification performed. On the advice of the makers, sensitivity to amoxycillin (Amoxil) was appraised in relation to a 25- $2 \mathrm{~g}$ ampicillin disc (Oxoid Ltd).

All patients were asked to attend the surgery one week after finishing treatment. Those who returned before completing a course of amoxycillin because of diarrhoea or a rash were given alternative chemotherapy and withdrawn from the trial. Patients were also eliminated from the trial if one or both of the initial pair of urine cultures failed to reach the level of significance (100 000 organisms $/ \mathrm{ml}$ of a urinary pathogen) or showed heavy contamination.

In patients whose two initial cultures were positive, and irrespective of whether the pathogen present was sensitive to ampicillin, a further urine culture was taken one week after the end of treatment. If a patient still had symptoms at this time an alternative antibiotic was prescribed and the case was recorded as a treatment failure. Six weeks after the end of amoxycillin treatment a final urine cuiture was taken from each patient. If this proved negative the case was recorded as successful. Patients with positive cultures were scored as failures of treatment and were examined in the department of urology for abnormalities of the urinary tract. If the organism isolated remained unchanged failure was scored as relapse, but when there was a change from the initial infecting organism failure was recorded as re-infection.

\section{Results}

During the 19 months covered by the trial 275 non-pregnant women attended the practice complaining of two of the following symptoms: frequency, dysuria, or loin pain. The number seen in each month varied from six to 23 .

Significant bacteriuria was found in 164 patients $\left(60^{\circ}{ }_{0}\right)$, but 38 of these provided only a single specimen of urine before treatment. Of the 126 patients who provided two specimens 120 were found to have infecting organisms that were sensitive to ampicillin. Ten of these patients did not provide complete follow-up urine specimens after treatment, so only the 110 remaining patients and six with ampicillinresistant organisms were analysed fully. Fifty-six patients received the three-day course of amoxycillin and 60 received the 10 -day course.

Of the six patients with ampicillin-resistant organisms three had Escherichia coli and three had Klebsiella sp. Urine cultures after treatment were negative in both the patients treated for 10 days and in three of the four treated for three days.

Table I lists the infections in the 110 patients with ampicillinsensitive organisms. Urine culture after treatment was negative in $49\left(85^{\circ}{ }_{0}\right)$ of the 58 patients treated for 10 days and in $42\left(81^{\circ}{ }_{0}\right)$ of the 52 patients treated for three days. The difference between the two groups was not significant $\left(\%^{2}-0 \cdot 07\right)$.

\section{PERSISTING INFECTION}

Examination of the urine of those patients in whom infection persisted after treatment indicated a difference in relapse and reinfection rates between the two treatment groups. In the three-day group infection was still present in 10 patients after treatment: eight had relapses and two were reinfected. In the 10-day group nine patients were still infected; five were reinfected and four relapsed. The numbers were too small to achieve significance.

More important to the patient is the elimination of symptoms after treatment. Nine patients in each group had some residual symptoms, but only nine out of these 18 patients were still infected (four patients in the 10-day group and five in the three-day group). In each treatment group there were five patients with symptomless bacteriuria after treatment.

Of the 19 patients with persisting bacteriuria after treatment 13 were further examined by intravenous pyelography, which showed a significant abnormality in four patients. In one case a single large renal calculus was found, and in another small calculi were present in both kidneys. A third patient had the changes of chronic pyelonephritis in one kidney and the fourth had a large post-micturition residual urine. Four further patients showed lesser degrees of postmicturition residual urine or distensible collecting systems (particularly on the right side) during compression of the ureter as part of the radiological examination.

\section{SIDE EFFECTS}

Of the 275 patients who originally presented with frequency, dysuria, or loin pain 138 were treated for three days and 137 for 10 days, and side effects of treatment were noted in $15(11 \%)$ and 21 $(15 \%)$ respectively (table II). This difference between the two regimens was insignificant $\left(\chi^{2}=1 \cdot 20\right)$.

TABLE II-Incidence of side effects to amoxycillin in all patients according to treatment regimen

\begin{tabular}{c|c|c|c|c}
\hline & $\begin{array}{c}\text { No of } \\
\text { patients }\end{array}$ & Thrush & $\begin{array}{c}\text { Diarrhoea } \\
\text { and nausea }\end{array}$ & $\begin{array}{c}\text { Rash and } \\
\text { pruritus }\end{array}$ \\
\hline $\begin{array}{c}137 \\
\text { 3-Day regimen }\end{array}$ & $\begin{array}{c}137 \\
138\end{array}$ & 3 & 6 & 10 \\
\hline Total & 275 & 8 & 12 & 16 \\
\hline
\end{tabular}

\section{Discussion}

The length of a course of treatment for urinary tract infection depends very much on the habits of the prescriber. There is no evidence to support the view that once bacteriuria has been eliminated additional benefit derives from continuing chemotherapy. Taking an antibiotic that has been shown to be effective against the organism responsible for the urinary infection sterilises the urine within 48 hours. $^{6}$

Most patients with urinary tract infections do not have a systemic illness such as that which occurs with acute pyelonephritis, and frequency and dysuria usually vanish two to three days after starting treatment. This reduces the patient's motivation to complete longer courses of treatment prescribed for one, two, or even more weeks. Failure to complete a course can lead to an accumulation of unused drugs at home, which constitutes a hazard to children and raises the possibility of subsequent self-treatment with deteriorating or inappropriate drugs. If short-term treatment is shown to be bacteriologically effective it seems irrational to continue chemotherapy long after symptoms have been relieved. On the other hand, although single-dose treatment with a long-acting sulphonamide (sulfametopyrazine) has been reported to be successful, ${ }^{7}$ patients will probably accept more readily a regimen in which chemotherapy continues until symptoms have abated.

The mechanism of action of the chemotherapeutic agent used to treat the infection is important. In the case of the long-acting sulphonamides there is a constant supply of un-ionised sulphonamide available for reabsorption, which permits the maintenance of bacteriostatic blood levels of the drug for seven days. In common with all penicillins, the aminopenicillins are bactericidal, and short-term chemotherapy using antibiotics with this property should be effective.

Our object was to establish whether a short course of an appropriate antibiotic was as effective as a more conventional 10-day course of treatment for urinary tract infections. The numbers in each group were almost equal (58 in the 10-day group, 52 in the three-day group). Two-thirds of the patients 
in each group gave a past history of urinary symptoms ( 37 in the 10-day group, 33 in the three-day group), and in both groups $E$ coli accounted for most of the infections (45 in the 10-day group, 42 in the three-day group).

Although reinfections were recorded as treatment failures, the cure rates obtained, nevertheless, compared favourably with figures from other series, ${ }^{8}$ in which reinfection was considered to be a failure of patient defence mechanism rather than of treatment. In our study of urinary infection in general practice the cure rate both symptomatically and bacteriologically was equally good for both treatment groups $(85 \%$ in the 10 -day group, $81 \%$ in the three-day group). We recommend the shorter, three-day course because it costs less and reduces the likelihood of patients accumulating unwanted uncontrolled drugs in their homes.
We thank Dr E A P Croydon of Beecham Pharmaceutical Division for help in designing this trial, Miss $J$ R Urwin of Bencard for undertaking statistical analysis, and Bencard for supplying Amoxil capsules.

\author{
References \\ ${ }^{1}$ Gallagher, D J A, Montgomerie, J E, and North, J D K, British Medical \\ fournal, 1965, 1, 622. \\ 2 Mond, N C, et al, Lancet, 1965, 1, 514. \\ 3 Gillespie, W A, et al, Lancet, 1971, 2, 675. \\ ${ }^{4}$ McAllister, T A, et al, Postgraduate Medical fournal, 1971, 47, suppl p 7. \\ 5 Mackey, J P, and Sandys, G H, British Medical fournal, 1965, 2, 1286. \\ 6 Charlton, C A C, et al, Postgraduate Medical fournal, 1970, 46, suppl p 30. \\ 7 Slade, N, and Crowther, S T, Britısh fournal of Urology, 1972, 44, 105. \\ ${ }^{8}$ Leigh, D A, Current Medical Research ard Opinion, 1972, 1, 10.
}

$+$

\title{
Experience of coronary care in diabetes
}

\author{
A D B HARROWER, B F CLARKE
}

British Medical fournal, 1976, 1, 126-128

\begin{abstract}
Summary
During 1968-73, 94 patients with diabetes were admitted to a coronary care unit (CCU) on 99 occasions with proved myocardial infarction. Altogether 24 of them $(25.5 \%)$ died, giving an overall mortality at the time of discharge of $24 \%$ for the total admissions. This was just significantly higher than the $19 \%$ mortality recorded among non-diabetics treated in the same period but was much lower than that among diabetics treated for myocardial infarction before the advent of CCUs. No definite correlation was found between the type of antidiabetic treatment and either mortality or the incidence of primary ventricular fibrillation. Patients with "poor" control of the diabetes before admission showed a significantly higher mortality than those with "good" control, but there was no significant difference in mortality between those with previous good control and non-diabetics.
\end{abstract}

\section{Introduction}

Reports made before the advent of coronary care units (CCU) emphasised the high mortality from acute myocardial infarction in diabetes. ${ }^{1-3}$ Apart from the results of one study, ${ }^{4}$ there is little information on mortality in diabetic patients admitted to CCUs and on whether such management has helped to reduce mortality. We have reported briefly our preliminary findings of such a study ${ }^{5}$ and present here a more detailed analysis of the results.

\section{Patients and methods}

During the six years $1968-73,53$ diabetic men (mean age $59 \pm$ SD 9 years) and 41 diabetic women (mean age $61 \pm 8$ years) were admitted to the CCU at this hospital on 54 and 45 occasions respectively with acute myocardial infarction. The diagnosis was confirmed by electro-

Diabetic and Dietetic Department, Royal Infirmary, Edinburgh EH4 2XU

A D B HARROWER, MB, MRCP, senior medical registrar

B F CLARKE, MB, FRCPED, consultant physician cardiographic and enzyme changes. ${ }^{6}$ All had had diabetes for at least six months. The patients represented $2 \cdot 7^{\circ}$ of the total admissions to the CCU for proved acute myocardial infarction over the same period, the referral area-that is, of general practices-for both diabetic and non-diabetic patients being identical. During the same period 10 further patients, all male (mean age 59 years), were diagnosed as diabetic after admission to the CCU. They are excluded from this analysis.

While in the CCU diabetic control was usually supervised by the cardiological team unless any problem arose, when a specialist was consulted. The patients' usual antidiabetic treatment was continued and modified when necessary. In accordance with the policy of the $\mathrm{CCU}^{6}$ the patients were kept in the unit for a mean of two days and then transferred to a general medical ward for further observation and management for a mean of 19 days, when they were discharged home.

Data were obtained from the records of the CCU and the diabetic department. The 94 patients (99 admissions) were divided into five subgroups according to their antidiabetic treatment, and the number on diet, sulphonylurea, biguanide, combined oral treatment, and insulin are shown in table I. Diabetic control was assessed from the mean of the blood glucose values obtained at the previous five clinic visits or during the previous two years, whichever period was the longer, with two arbitrary groups-"good" control (mean blood glucose up to $10 \mathrm{mmol} / 1(180 \mathrm{mg} / 100 \mathrm{ml})$, and "poor" control (mean blood glucose greater than $10 \mathrm{mmol} / \mathrm{l})$.

\section{Results}

Table I shows the mortality up to the time of discharge from hospital in the various subgroups, with respect to age and the duration of diabetes. Altogether 24 patients $\left(25.5^{\circ}\right)$ died, giving an overall mortality of $24^{\circ}$ for the admissions. The mortality among non-diabetics admitted to the CCU in the same period was $19^{\circ}, \ldots$ This difference is statistically significant $\left(\chi^{2}=2.85\right.$; P 0.05). The mean age at death was similar for both the diabetics (63.2 years) and non-diabetics (62.0 years). In addition, as has been found among non-diabetics treated in other CCUs, ${ }^{6}{ }^{7}$ there was a progressive rise in mortality with each decade of age (see fig).

Analysis of the relation of treatment to mortality showed that patients on diet alone had a mortality of $23^{\circ}{ }^{\circ}$, , those given sulphonylureas, biguanides, and combined treatment had mortalities of $30^{\circ} \%$, $25^{\circ}{ }^{\circ}$, and $29^{\prime \prime}$, respectively, and the insulin group had a mortality of $17^{\circ} \mathrm{o}$. None of these differences were significant. Analysis of the individual subgroups, including all patients on oral agents, failed to confirm any significant difference in mortality from the non-diabetic patients.

Table II shows mortality related to the degree of diabetic control before admission to the CCU. In every treatment subgroup the proportion of patients with good control was greater in those who survived than in those who died, and patients with poor control had 